\title{
Application of Particle Swarm Optimization in Solving Economic Dispatch with Multiple Fuel Options
}

\author{
PK Olulope *, OM Amusan and CE Okafor \\ Department of Electrical and Electronic Engineering, Ekiti State University Ado-Ekiti, Nigeria
}

Global Journal of Engineering and Technology Advances, 2021, 07(03), 008-023

Publication history: Received on 25 April 2021; revised on 27 May 2021; accepted on 29 May 2021

Article DOI: https://doi.org/10.30574/gjeta.2021.7.3.0075

\begin{abstract}
Minimizing electricity generation cost which includes fuel cost, emission cost, operation/maintenance cost and network loss cost of multiple operating units has been a major issue in the power sector. The economic dispatch has the objective of allocating different loads to the power generators in such a manner that the total fuel cost is minimized while all operating constraints are satisfied. Conventional optimization methods assume generator cost curves to be continuous and monotonically increasing, but modern generators have a variety of nonlinearities in their cost curves making this assumption inaccurate, and the resulting approximate dispatches cause a lot of revenue loss. Computational intelligence optimization like Particle Swarm Optimization performs better for such problems. To know the effectiveness and efficiency in solving economic dispatch, this paper proposes the application of particle swarm optimization. The mathematical model of economic dispatch is developed and then, Particle Swarm Optimization is developed to solve the economic dispatch problem using 3-generator and 6-generator system with multiple fuel option. The test results clearly demonstrated that particle swarm optimization which is capable of achieving global solutions is simple, excellent computationally efficiency and has better and stable dynamic convergence characteristics with a high probability.
\end{abstract}

Keywords: Economic Dispatch, Optimization techniques, Heuristic programming, Particle Swarm Optimization, multifuel option, Non-linear constraint

\section{Introduction}

The cost of electricity is increasing globally due to high cost of fossil fuel especially in countries where fossil fuels are not vastly deposited. In a competitive electricity market, to meet customers demand at the same time reducing the cost of generation becomes a major concern to generating company. To address this problem and save significant revenue, Economic dispatch which involves the allocation of power demand among generators in such a manner that will minimize the total fuel cost and maintain physical and operational constraint has been a hot area of research in recent time. It is one of the major challenge confronting power system operators which before now had been handled by conventional optimization algorithms such as Lamda iteration, quadraically constrained programming base point participation factor[1] gradient method, Newton method [2]. In the past, the cost function is approximated to be monotonically increasing in quadratic or piecewise-linear order[3]. This assumption is not valid because the cost functions of modern generators possess higher order of nonlinearities making the equations complex, non-convex with multiple minimal points resulting into serious challenge of locating global minimal[4]. The complexities and nonlinearity is as a result of valve point loading[5], prohibited operating zones [6] and ramp rate limits of generators[7]etc. Conventional optimization methods are ineffective is to model this complexities introduced due to nonlinearities of the modern generators. To achieve a fast and near global optimal solution, meta-heuristic optimization techniques have been proposed in literatures. Meta-heuristic optimization such as evolutionary algorithm (e.g Genetic algorithm), physical-based algorithm (e.g Gravitational Local Search, Big-Bang Big-Crunch (BBBC) and swarm Intelligence (e.g

\footnotetext{
${ }^{*}$ Corresponding author: PK Olulope

Department of Electrical and Electronic Engineering, Ekiti State University Ado-Ekiti, Nigeria. 
particle Swarm Optimization, ant colony). Today, swarm intelligence is widely used in the field of optimization because of its ability to preserve information, save the best information in the memory, the ease of implementation[8]. These algorithms mostly mimic the social behavior of swarms, herds, flocks, or schools of creatures in nature. The commonest and widely used one is particle Swarm Optimization (PSO)[8]

Particle swarm optimization (PSO) is a population- based meta-heuristic optimization and it iteratively optimize a problem using the best function or quality. Each particle in the population is moved in the search space influenced by its local best known position until the best known position is achieved in the search space. Particle swarm optimization has been researched extensively in the area of economic dispatch. Due to its flexibility, robustness, simplicity, fast convergence, it has been widely accepted in solving economic dispatch problem.

The author in [9] proposed the use of PSO to minimize the cost function as a single objective function in 6-generating unit system while the author in [10], [11] used PSO to solve non- smooth cost function with equality and inequality constraint. Ref deployed the use of PSO to solved economic dispatch problem considering constraint such as such as ramp rate limits, prohibited operating zone, and non-smooth cost functions and ref [12] investigated the use of PSO in solving economic dispatch with multiple fuel option subject to power balance and operating limit constraints. This research consider the use of PSO in solving economic dispatch problem considering power balance limit, operating limit constraint and effect of line losses with multiple fuel option resulting into nonsmooth cost function. All the paper reviewed only considered nonsmooth cost function with assumption that the line losses are neglected. The practical economic dispatch problem does not follow this track but involves transmission line losses and other constraint. The rest of the chapter is organized as follow:

\section{Literature review}

\subsection{Review of Economic Dispatch}

Economic Dispatch (ED) is defined as the process of allocating total power demand among committed generating unit economically at the same time satisfying various constraints distributing available load to the generating units so as save cost. In static economic dispatch, the objective of the conventional economic dispatch problem is to minimize the total cost of thermal generating units while satisfying various constraints including power balance and generator power limits. In the economic dispatch problem with multiple fuel options, the piecewise quadratic function is used to represent the multiple fuels which are available for each generating units[13]. There have been many algorithms proposed for economic dispatch. These include:

- Merit Order Loading

- Range Elimination to save cost

- Binary Section

- Secant Section

- Graphical/Table Look-Up

- Convex Simplex

- Dantzig-Wolf Decomposition etc.[8]

The following are well-known examples of "intelligent" algorithms that use clever simplifications and methods to solve computationally complex problems.

- Swarm Intelligence

- Tabu Search

- $\quad$ Simulated Annealing

- Genetic Algorithms

- Artificial Neural Networks

- $\quad$ Support Vector Machines[8]

\subsection{Review of Particle Swarm Optimization}

Kennedy and Eberhart [6] developed a particle swarm optimization algorithm based on the behaviour of individuals (i.e., particles or agents) of a swarm. Its roots are in zoologist's modelling of the movement of individuals within a group. It has been noticed that members of the group seem to share information among them, a fact that leads to increased 
efficiency of the group [9]. The PSO algorithm searches in parallel using a group of particles. Each particle corresponds to a candidate solution to the problem. A particle moves toward the optimum based on its present velocity, its previous experience, and the experience of its neighbours. In an $\mathrm{n}$-dimensional search space, the position and velocity of particle are represented as vectors $X_{i}=\left(x_{i 1} \ldots . . . X_{i n}\right)$ and $V_{i}=\left(V_{i 1} \ldots . . . V_{i n}\right)$, where the dimension represents the number of components. Let Pbest $_{i}=\left(X^{P_{11} \ldots \ldots . . . X^{P}}\right.$ in $)$ and Gbest $=\left(X^{G_{i 1} \ldots . . . . X^{G}}{ }_{i n}\right)$ be the best position of particle and its neighbour's best position so far, respectively. The modified velocity and position of each particle can be calculated as follows:

$V_{i}^{k+1}=w \cdot V_{i}^{k}+c_{i} \cdot r n_{1} \cdot\left(\right.$ Pbest $\left._{i}^{k}-X_{i}^{k}\right)+c_{2} \cdot r n_{2} \cdot\left(\right.$ Gbest $\left._{i}^{k}-X_{i}^{k}\right)$

$X_{i}^{k+1}=X_{i}^{k}+V_{i}^{k+1}$

Where

$\begin{array}{lc}V_{i}^{k} & \text { Velocity of Particle } i \text { at iteration } k ; \\ w & \text { Inertia weight factor; } \\ c_{i}, c_{2} & \text { Acceleration coefficient; } \\ r n_{1}, r n_{2} & \text { Random number between } 0 \text { and } 1 ; \\ X_{i}^{k} & \text { Position of particle } i \text { at iteration } k ;\end{array}$

The search mechanism of the PSO using the modified velocity and position of individual based on (1) and (2) is the figure below:

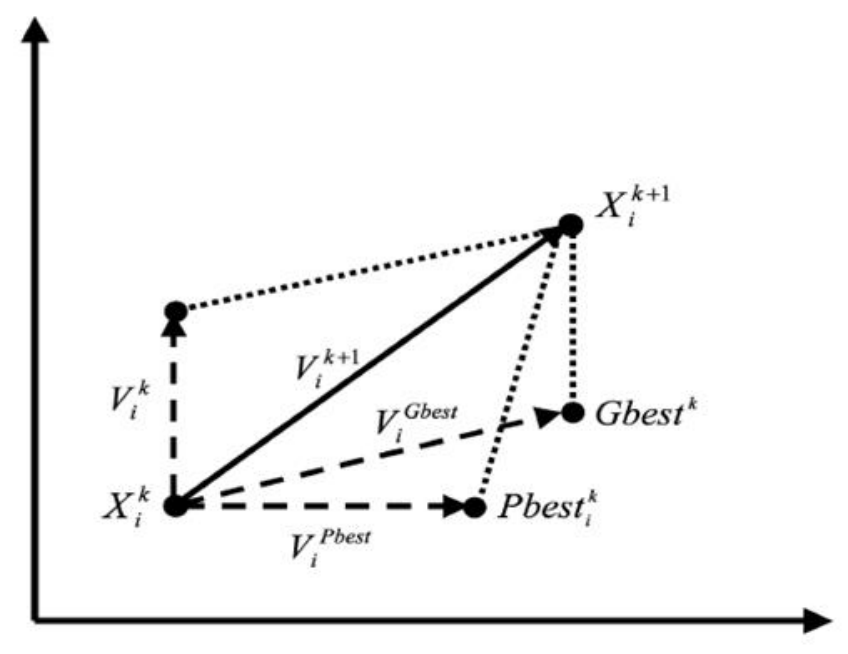

Figure 1: The search mechanism of the particle swarm optimization[14]

In this paper, the approach to implement the particle swarm optimization algorithm will be described in solving the economic dispatch problems. The process of the particle swarm optimization algorithm can be summarized as follows:

- Initialization of a group at random while satisfying constraints.

- Velocity and p osition updates while satisfying constraints.

- Update of Pbest and Gbest.

- Activation of space reduction strategy.

- $\quad$ Go to Step 2 until satisfying stopping criteria.[10]

\subsection{Initialization and Structure of Individuals}

In the initialization process, a set of individuals is created at random. In this paper, the structure of an individual for economic dispatch problem is composed of a set of elements (i.e., generation outputs). Therefore, individual's position at iteration 0 can be represented as the vector of $X_{i}^{0}=\left(x_{i 1}^{0}, \ldots . ., x_{i n}^{0}\right)$ where $n$ is the number of generators [10]

The velocity of individual $i$ (i.e., $\left.V_{i}^{0}=\left(v_{i 1}^{0}, \ldots . ., v_{i n}^{0}\right)\right)$ corresponds to the generation update quantity covering all generators. The elements of position and velocity have the same dimension, i.e., MW in this case. Note that the 
summation of all elements of individual $i$ (i.e., $\sum_{j=1}^{n} P_{i j}^{0}$ ) should be equal to the total system demand $P_{D}$ and the created element $j$ of individual $i$ at random (i.e., $P_{i j}^{0}$ ) should be located within its boundary. Although we can create element of individual at random satisfying the inequality constraint by mapping $[0,1]$ into $\left[P_{j m i n}, P_{j m a x}\right]$, it is necessary to develop a new strategy to handle the equality constraint. To do this, the following procedure is suggested for any individual in a group:

Step 1) Set $j=1$.

Step 2) Select an element (i.e., generator) of an individual at random.

Step 3) Create the value of the element (i.e., generation output) at random satisfying its inequality constraint.

Step 4) If $\mathrm{j}=n$ - 1 then go to Step 5 ; otherwise and $j=j+1$ go to Step 2 .

Step 5) the value of the last element of an individual is determined by subtracting $\sum_{j=1}^{n-1} P_{i j}^{0}$ from the total system demand, $P_{D}$. If the value is in the range of its operating region then go to Step 6; otherwise go to Step 1.

Step 6) Stop the initialization process. [10]

After creating the initial position of each individual, the velocity of each individual is also created at random. The following strategy is used in creating the initial velocity:

$$
\left(P_{j \min }-\varepsilon\right)-P_{i j}^{0} \leq v_{i j}^{0} \leq\left(P_{j \max }+\varepsilon\right)-P_{i j}^{0}
$$

Where $\varepsilon$ is a small positive real number. The velocity of element $j$ of individual $i$ is generated at random within the boundary. The developed initialization scheme always guarantees to produce individuals satisfying the constraints while maintaining the concept of the PSO algorithm. The initial Pbest $t_{i}$ of individual $i$ is set as the initial position of individual $i$ and the initial Gbest is determined as the position of an individual with minimum payoff of the objective function. [10].

\subsection{Velocity Update}

In the velocity updating process, the values of parameters such as $w, c_{i}$, and $c_{2}$ should be determined in advance. The constants $c_{i}$ and $c_{2}$ represent the weighting of the stochastic acceleration terms that pull each particle toward the Pbest $t_{i}$ and Gbest positions. Suitable selection of inertia weight can provide a balance between global exploration and local exploitation, and results in a lower number of iterations to find the optimal solution. In general, to enhance the convergence characteristics, the inertia weight factorw is designed to decrease linearly (i.e., Inertia Weight Approach (IWA) [11], [12], descending from $w_{\min }$ to $w_{\max }$ to as follows:

$$
w^{k}=w_{\max }-\frac{w_{\max }-w_{\min }}{\text { iter }_{\max }} \times K
$$

Where $i t e r_{\max }$ corresponds to the maximum iteration number. Using the new position $X_{i}^{k+1}$, the Pbest $t_{i}$ and Gbest are updated at iteration $k+1$ using the greedy selection.

\subsection{Position Modification Considering Constraints}

The position of each individual is modified by

$$
P_{i j}^{k+1}=\left\{\begin{array}{c}
P_{i j}^{k}+V_{i j}^{k+1} \text { if } P_{i j, \text { min }} \leq P_{i j}^{k}+V_{i j}^{k+1} \leq P_{i j, \text { max }} \\
P_{i j, \text { min }} \text { if } P_{i j}^{k}+V_{i j}^{k+i}<P_{i j, \min } \\
P_{i j, \text { max }} \text { if } P_{i j}^{k}+V_{i j}^{k+i}>P_{i j, \max }
\end{array}\right.
$$


Figure 2 Illustrates how the position of element $j$ of individual $i$ is adjusted to its maximum when the over-velocity situation occurs.

Although the aforementioned method always produces the position of each individual satisfying the inequality constraints of the generator operating limit $\left(P_{i, \min } \leq \mathrm{P}_{\mathrm{i}} \leq \mathrm{P}_{\mathrm{i}, \mathrm{max}} ; \mathrm{i}=1, \ldots, n\right)$, the problem of equality constraint still remains to be resolved. Therefore, it is necessary to develop a new strategy such that the summation of all elements in an individual (i.e., $\sum_{j=1}^{n} P_{i j}^{k}$ ) is equal to the total system demand. [11]. [10]

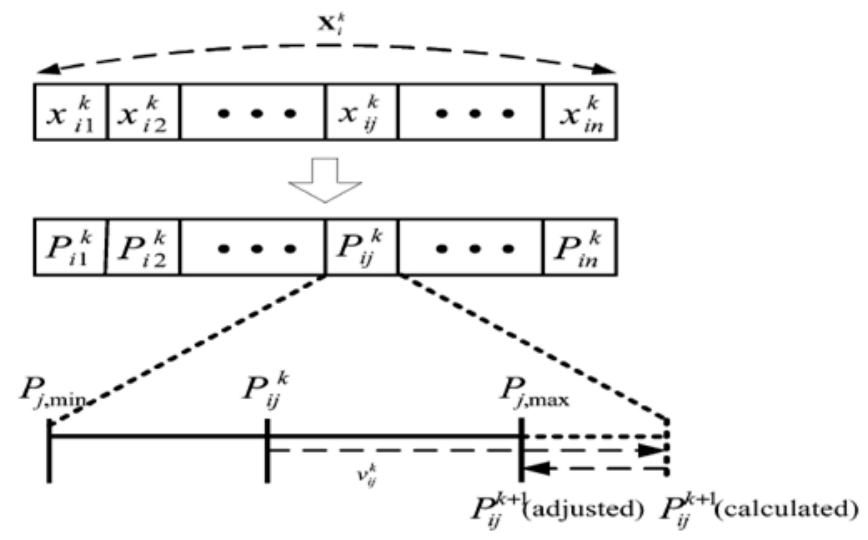

Figure 2 Adjustment strategy for an individual's position within boundary [10]

\subsection{Update of Pbest and Gbest}

The Pbest of each individual at iteration $k+1$ is updated as follows:

$$
\begin{aligned}
\text { Pbest }_{i}^{k+1}=X_{i}^{k+1} & \text { if } T C_{i}^{k+1}<T C_{i}^{k+1} \\
\text { Pbest }_{i}^{k+1}=\text { Pbest }_{i}^{k+1} & \text { if } T C_{i}^{k+1} \geq T C_{i}^{k+1}
\end{aligned}
$$

Where

$T C_{i}$ the object function evaluated at the position of individual $i$.

Additionally, Gbest at iteration $k+1$ is set as the best evaluated position amongPbest ${ }_{i}^{k+1} \cdot$ [10].

\subsection{Space Reduction Strategy}

To accelerate the convergence speed to the solutions, the multiple particle swarm optimization has introduced the search space reduction strategy. This strategy is activated in the case when the performance is not increased during a pre-specified iteration period. In this case, the search space is dynamically adjusted (i.e., reduced) based on the "distance" between the Gbest and the minimum and maximum output of generator $j$. To determine the adjusted minimum/maximum output of generator $i$ at iteration $k$, the distance is multiplied by the predetermined step-size $\Delta$ and subtracted (added) from the maximum (minimum) output at iteration as described in (8 and 9)

$$
\begin{gathered}
P_{j \max }^{k+1}=P_{j \max }^{k}-\left(P_{j \max }^{k}-\text { Gbest }_{j}^{k}\right) \times \Delta \\
P_{j \min }^{k+1}=P_{j \min }^{k}-\left(P_{j \text { min }}^{k}-\text { Gbest }_{j}^{k}\right) \times \Delta
\end{gathered}
$$

Fig. 3 illustrates how the search space of each generator is dynamically reduced when activated. 


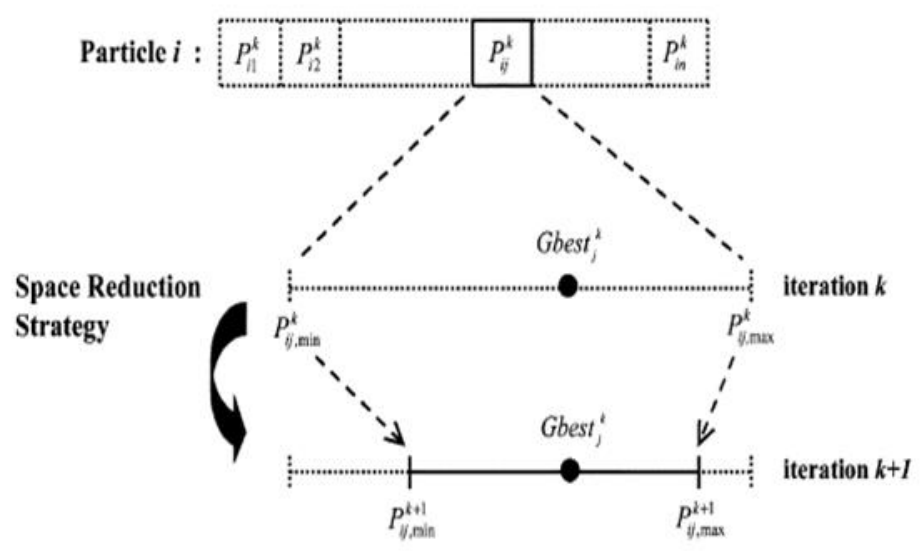

Figure 2 Schematic of the dynamic space reduction strategy[10].

\subsection{Stopping Criteria}

The multi-objective particle swarm optimization is terminated if the iteration approaches to the predefined maximum iteration. [10].

\section{Methodology}

\subsection{Modelling of Economic Dispatch and Problem Formulation}

The objective of the conventional economic dispatch problem is to minimize the total cost of thermal generating units while satisfying various constraints including power balance and generator power limits. In the economic dispatch problem with multiple fuel options, the piecewise quadratic function is used to represent the multiple fuels which are available for each generating units [13]. Therefore, the objective of the economic dispatch problem with multiple fuel options is to find a suitable fuel for each generating unit so as their total cost is minimized while satisfying different constraints including power balance and generation limits.

Mathematically, the problem is formulated as follows:

$\operatorname{Min} F=\sum_{i=1}^{n} F_{i}\left(P_{i}\right)$

In general, a piecewise quadratic function is used to represent the input-output curve of a generator with multiple fuels and described as

$F_{i}\left(P_{i}\right)=\left\{\begin{array}{c}a_{i 1}+b_{i 1} P_{i}+c_{i 1} P_{i}^{2}, \text { Fuel } 1 P_{\text {imin }} \leq P_{i} \leq P_{i 1} \\ a_{i 2}+b_{i 2} P_{i}+c_{i 2} P_{i}^{2}, \text { Fuel } 2 P_{i 1} \leq P_{i} \leq P_{i 2} \\ \cdot \\ \cdot \\ \cdot \\ a_{i k}+b_{i k} P_{i}+c_{i k} P_{i}^{2}, \text { Fuel } k P_{i k-1} \leq P_{i} \leq P_{\text {imax }}\end{array}\right.$

Where

$a_{i k}, b_{i k}, c_{i k} \quad$ Cost Coefficient for unit i for fuel type $k$

$\mathrm{Pi}_{\mathrm{i}} \quad$ Output power of unit i (MW)

$\mathrm{P}_{\text {imin, }} \mathrm{P}_{\mathrm{imax}} \quad$ Lower and Upper generation limits of unit $\mathrm{i}$

Subject to 
a) Power balance constraint

$\sum_{i=1}^{n} P_{i}-P_{L}-P_{D}=0$

Where the power loss is approximately calculated by Kron's formula

$$
P_{L}=\sum_{i=1}^{N} \sum_{i=1}^{N} P_{i} B_{i j} P_{j}+\sum_{i=1}^{N} B_{0 i} P_{i}+B_{00}
$$

b) Generator operating limits

$P_{i, \min } \leq \mathrm{P}_{\mathrm{i}} \leq \mathrm{P}_{\mathrm{i}, \max } ; \mathrm{i}=1, \ldots, \mathrm{N}$

Where

$\begin{array}{ll}P_{i} & \text { Output power of unit } i \\ P_{D} & \text { Total load demand of the system (MW) } \\ P_{L} & \text { Total network loss of the system (MW) } \\ B_{i j, B_{o i}, B_{o o}} & \text { Transmission loss formula coefficients }\end{array}$

Table 1 Data for 3-Unit System

\begin{tabular}{|l|l|l|l|l|}
\hline $\mathbf{S} / \mathbf{N}$ & $\begin{array}{l}\text { Generating } \\
\text { Units }\end{array}$ & $\begin{array}{l}\text { Lower Limit, } \mathbf{P}_{\min } \\
(\mathbf{M W})\end{array}$ & $\begin{array}{l}\text { Upper Limit, } \mathbf{P}_{\max } \\
\mathbf{( M W )}\end{array}$ & $\begin{array}{l}\text { Cost Coefficient } \\
\mathbf{( a , b}, \mathbf{c})\end{array}$ \\
\hline 1 & Generator 1 & 10 & 85 & $0.008,7,200$ \\
\hline 2 & Generator 2 & 10 & 80 & $0.009,6.3,180$ \\
\hline 3 & Generator 3 & 10 & 70 & $0.007,6.8,140$ \\
\hline
\end{tabular}

$\begin{array}{ccc}B_{\text {if }}=0.000218 & 0.000093 & 0.000028 \\ 0.000093 & 0.000228 & 0.000017 \\ 0.000028 & 0.000031 & 0.000015\end{array}$

$B_{0 i}=0.0003 \quad 0.0031 \quad 0.0015$

$B_{00}=0.030523$

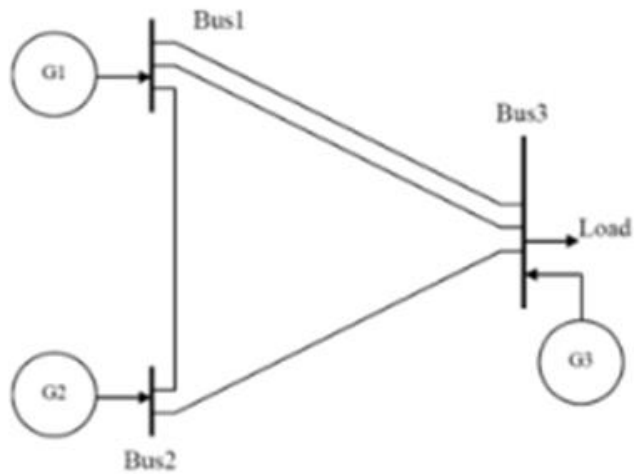

Figure 5 Typical 3-Unit system 
Table 2 Data for 6-Unit System

\begin{tabular}{|l|l|l|l|}
\hline $\begin{array}{l}\text { Generating } \\
\text { Unit }\end{array}$ & $\begin{array}{l}\text { Lower Limit, } P_{\min } \\
(\mathrm{MW})\end{array}$ & $\begin{array}{l}\text { Upper Limit, } \mathrm{P}_{\max } \\
(\mathrm{MW})\end{array}$ & $\begin{array}{l}\text { Cost Coefficient } \\
(\mathrm{a}, \mathrm{b} \text { and c) }\end{array}$ \\
\hline 1 & 100 & 500 & $0.007,7,240$ \\
\hline 2 & 50 & 200 & $0.0095,10,200$ \\
\hline 3 & 80 & 300 & $0.009,8.5,300$ \\
\hline 4 & 50 & 150 & $0.008,11,200$ \\
\hline 5 & 50 & 200 & $0.008,10.5,220$ \\
\hline 6 & 50 & 120 & $0.0075,12,120$ \\
\hline
\end{tabular}

$$
\begin{array}{cccccc}
0.000014 & 0.000017 & 0.000015 & 0.000019 & 0.000026 & 0.000022 \\
B_{i j}=0.000017 & 0.00006 & 0.000013 & 0.000016 & 0.000015 & 0.00002 \\
0.000015 & 0.000013 & 0.0000650 .000017 & 0.000024 & 0.000019 \\
0.000019 & 0.000016 & 0.0000170 .000071 & 0.00003 & 0.000025 \\
0.000026 & 0.000015 & 0.000024 & 0.00003 & 0.000069 & 0.000032 \\
0.000022 & 0.00002 & 0.000019 & 0.000025 & 0.000032 & 0.000085 \\
& & & & \\
B_{0 i}=0 & B_{00}=0
\end{array}
$$

$\begin{array}{cccccc}0.000019 & 0.000016 & 0.000017 & 0.000071 & 0.00003 & 0.000025 \\ 0.000026 & 0.000015 & 0.000024 & 0.00003 & 0.000069 & 0.000032 \\ 0.000022 & 0.00002 & 0.000019 & 0.000025 & 0.000032 & 0.000085\end{array}$

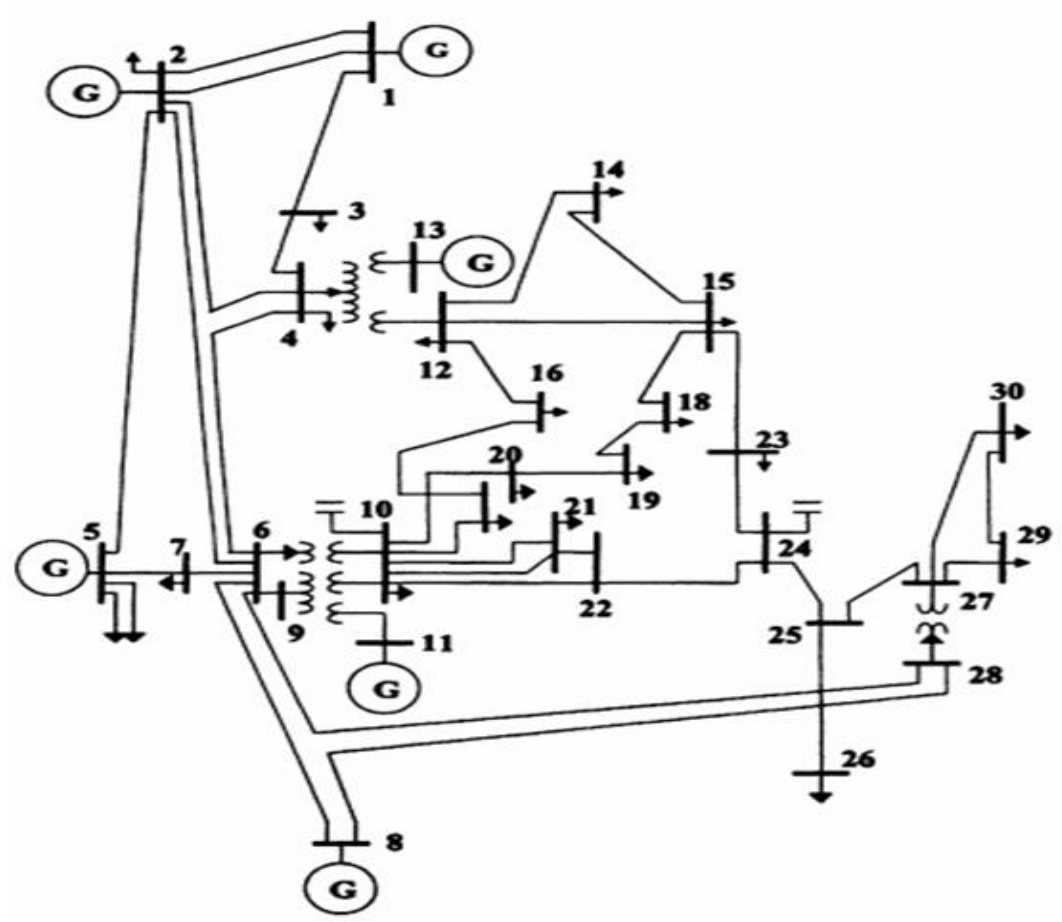

Figure 3 Typical 6-Unit system 


\section{Results}

\subsection{Test Strategy}

To verify the feasibility and effectiveness of Particle Swarm Optimization (PSO) in solving economic dispatch, the heuristic algorithms was applied to

3-unit system with transmission losses

3-unit system without transmission losses

6-unit system with transmission losses

6-unit system without transmission losses

3-unit system with multiple fuel options

The economic dispatch problem was solved using particle swarm optimization and the performance of each generator has been judged using MATLAB 8.1.0 on an Intel(R) Pentium(R) N3540 processor, 2.16GHz with 4GB RAM.

\subsection{Parameter Determination Strategy}

The several parameters to be determined for the implementation of the particle swarm optimization such as $w, c_{1}$ and $c_{2}$ in . In this journal, these parameters have been determined and to avoid the problem of the curse of dimensionality, the procedures and strategies are determined as follows:

1. The values of $c_{1}$ and $c_{2}$ have the same value, which implies the same weights are given between Pbest and Gbest in the evolution processes.

2. The values of $w$ are varied from 0.9 to 0.4

The parameters of the PSO are as follows

- Population size is 50

- Number of generation is 500

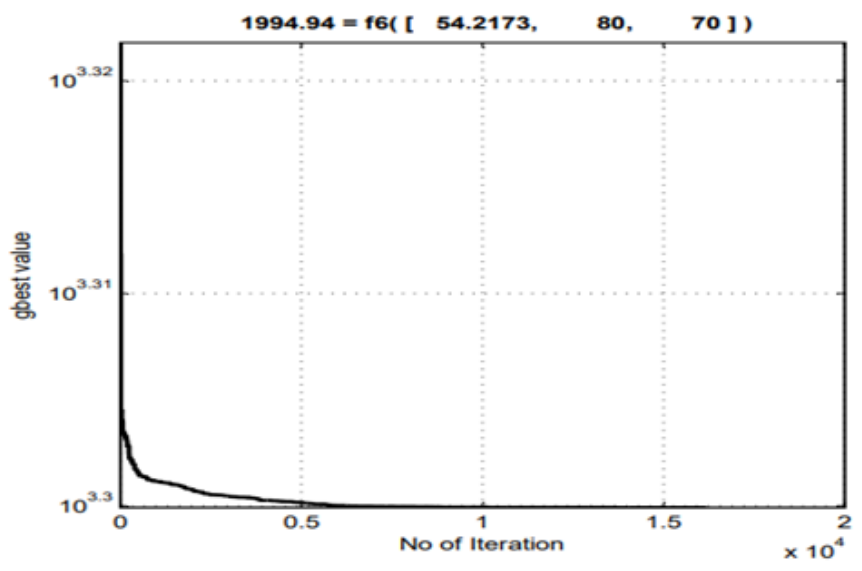

Figure 4 Convergence Characteristics of PSO for 3-unit system 


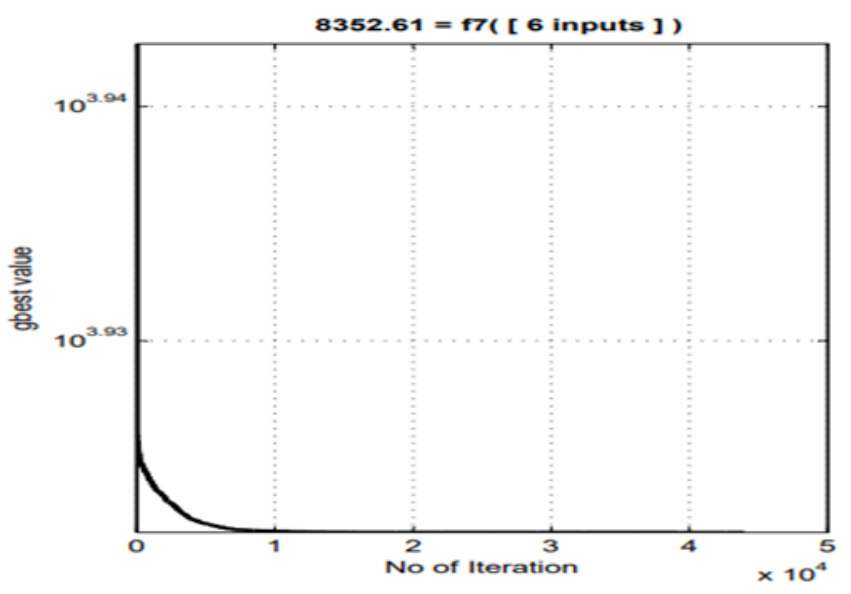

Figure 5 Convergence Characteristics of PSO for 6-unit system

\subsection{Solution Quality}

The particle swarm optimization was tested to know its effectiveness in minimizing generation cost and as well meeting the various load demands. The first test system has three-generating units and the parameters of the 3-Unit system has transmission loss coefficient represented in B-matrix form as shown in table 1. The output of the particle swarm optimization are presented in table 3 . At various load demand (with $10 \mathrm{MW}$ increment), the result is given by particle swarm optimization algorithm in term of generation cost and power loss minimization.

Table 3 Results by particle swarm optimization at different load values.

\begin{tabular}{|l|l|l|l|l|l|}
\hline $\begin{array}{l}\text { Power } \\
\text { Demanded } \\
\text { (MW) }\end{array}$ & $\begin{array}{l}\text { Gen } \\
\mathbf{1} \\
\text { (MW) }\end{array}$ & $\begin{array}{l}\text { Gen } \\
\mathbf{( M W )}\end{array}$ & $\begin{array}{l}\text { Gen } \\
\mathbf{3} \\
\text { (MW) }\end{array}$ & $\begin{array}{l}\text { Total } \\
\text { Cost } \\
\text { (\#/hr.) }\end{array}$ & $\begin{array}{l}\text { Power } \\
\text { Loss } \\
\text { (MW) }\end{array}$ \\
\hline 100 & 16.64 & 49.69 & 34.78 & 1219 & 1.08 \\
\hline 110 & 19.70 & 52.90 & 38.72 & 1293 & 1.30 \\
\hline 120 & 23.26 & 55.73 & 42.56 & 1368 & 1.53 \\
\hline 130 & 26.30 & 58.78 & 46.73 & 1444 & 1.78 \\
\hline 140 & 29.72 & 61.40 & 50.96 & 1521 & 2.05 \\
\hline 150 & 32.74 & 64.82 & 54.82 & 1598 & 2.35 \\
\hline 160 & 36.03 & 67.42 & 59.24 & 1676 & 2.65 \\
\hline 170 & 39.37 & 70.50 & 63.15 & 1754 & 2.99 \\
\hline 180 & 43.00 & 73.28 & 67.09 & 1834 & 3.35 \\
\hline 190 & 46.88 & 76.90 & 70.00 & 1914 & 3.74 \\
\hline 200 & 54.22 & 80.00 & 70.00 & 1995 & 4.19 \\
\hline 210 & 64.69 & 80.00 & 70.00 & 2078 & 4.65 \\
\hline 220 & 75.20 & 80.00 & 70.00 & 2164 & 5.17 \\
\hline
\end{tabular}




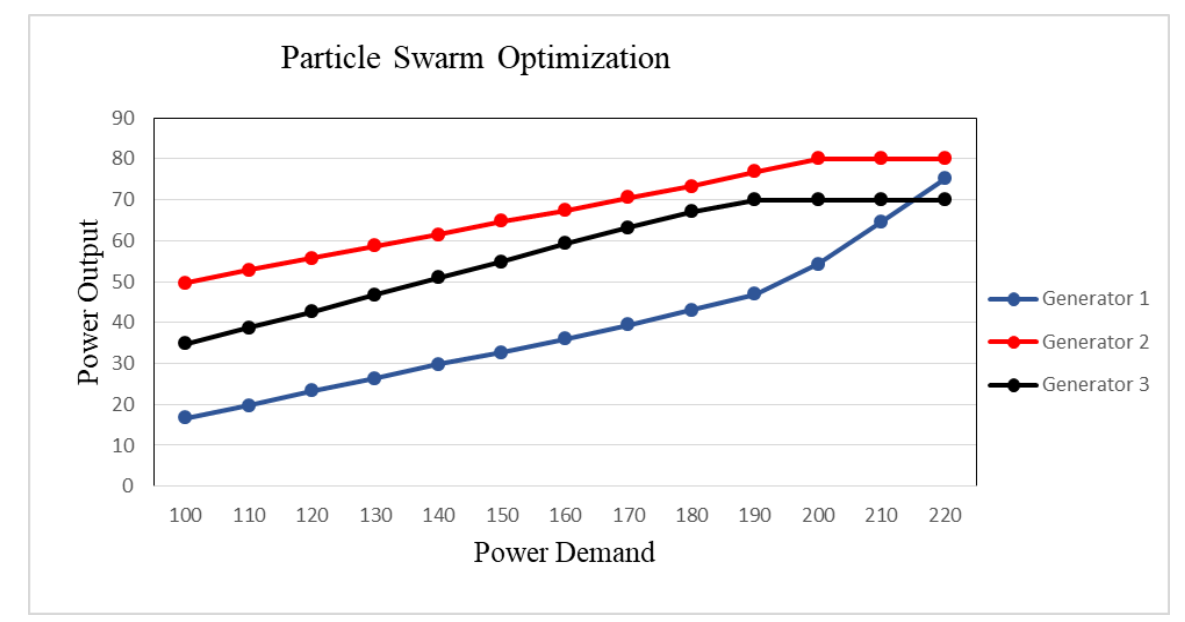

Figure 6 Power Output of three generators using Particle Swarm Optimization

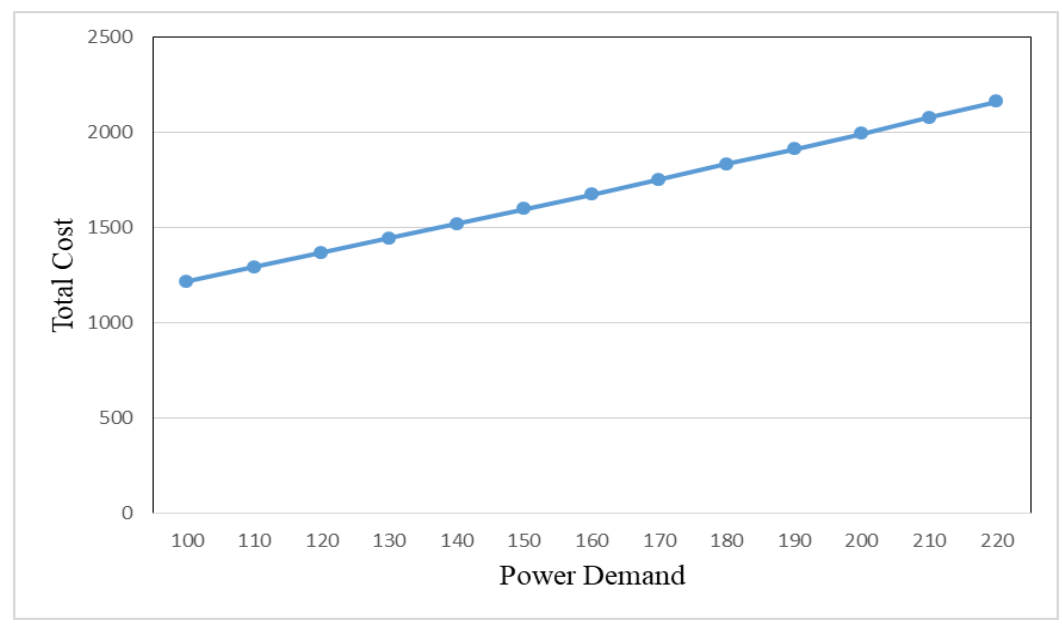

Figure 7 Total Cost using Particle Swarm Optimization

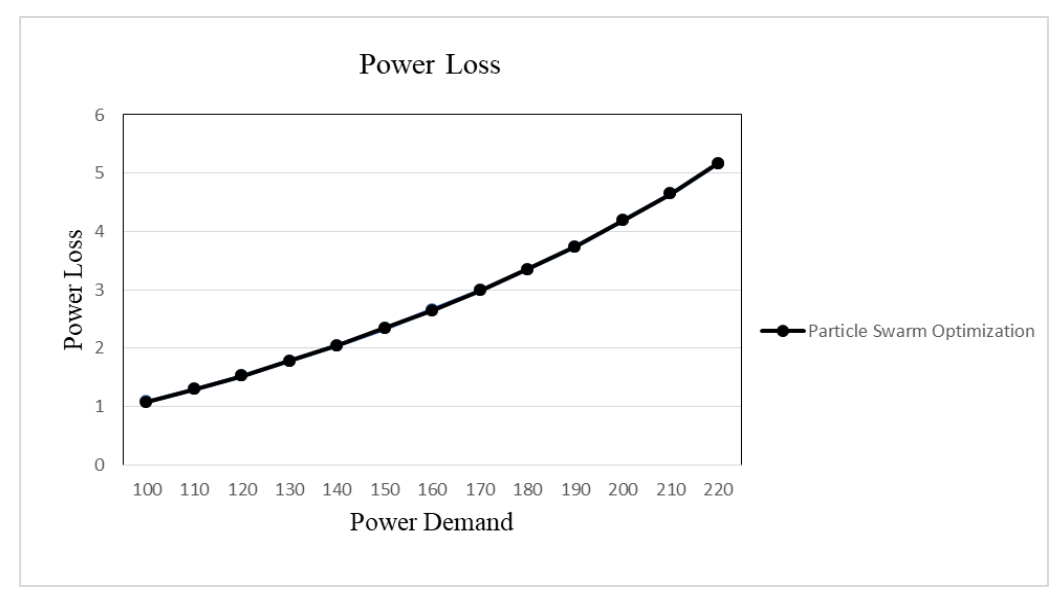

Figure 8 Total Power loss for three generators

Considering the same 3-Unit system without transmission losses (from Table 1), it is found that the global solution of particle swarm optimization has a very high probability as shown in Table 4, exactly satisfying the equality and 
inequality constraints. Although particle swarm optimization and genetic algorithm have different load sharing for different load demand, the cost of generation remain the same for various load demands.

Table 4 Results by particle swarm optimization without transmission loss at different load values.

\begin{tabular}{|c|c|c|c|c|}
\hline $\begin{array}{l}\text { Power } \\
\text { Demanded } \\
(\mathrm{MW})\end{array}$ & $\begin{array}{l}\text { Gen } \\
1 \\
(\mathrm{MW})\end{array}$ & $\begin{array}{l}\text { Gen } \\
2 \\
(M W)\end{array}$ & $\begin{array}{l}\text { Gen } \\
3 \\
(M W)\end{array}$ & $\begin{array}{l}\text { Total Cost } \\
\text { (\#/hr.) }\end{array}$ \\
\hline 100 & 15.83 & 52.21 & 31.96 & 1211 \\
\hline 110 & 18.65 & 55.54 & 35.81 & 1283 \\
\hline 120 & 22.23 & 58.54 & 39.23 & 1357 \\
\hline 130 & 25.32 & 61.07 & 43.61 & 1431 \\
\hline 140 & 28.90 & 64.15 & 46.96 & 1505 \\
\hline 150 & 32.11 & 67.23 & 50.67 & 1580 \\
\hline 160 & 35.25 & 70.36 & 54.39 & 1655 \\
\hline 170 & 38.59 & 73.11 & 58.30 & 1731 \\
\hline 180 & 41.93 & 75.92 & 62.15 & 1807 \\
\hline 190 & 45.13 & 78.92 & 65.95 & 1884 \\
\hline 200 & 50 & 80 & 70 & 1962 \\
\hline 210 & 60 & 80 & 70 & 2041 \\
\hline 220 & 70 & 80 & 70 & 2121 \\
\hline
\end{tabular}

Increasing the number of generating units to six and using particle swarm optimization to solve the economic dispatch problem of the 6-unit system, Table 2 shows the parameters of the 6-Unit system with their cost coefficient. The solution is shown in table 5 .

Table 5 Result by particle swarm optimization with transmission loss at different load values.

\begin{tabular}{|c|c|c|c|c|c|c|c|c|}
\hline $\begin{array}{l}\text { Power } \\
\text { Demanded } \\
(\mathrm{MW})\end{array}$ & $\begin{array}{l}\text { Unit } 1 \\
\text { (MW) }\end{array}$ & $\begin{array}{l}\text { Unit } 2 \\
(M W)\end{array}$ & $\begin{array}{l}\text { Unit } 3 \\
\text { (MW) }\end{array}$ & $\begin{array}{l}\text { Unit } 4 \\
\text { (MW) }\end{array}$ & $\begin{array}{l}\text { Unit } 5 \\
\text { (MW) }\end{array}$ & $\begin{array}{l}\text { Unit } 6 \\
\text { (MW) }\end{array}$ & $\begin{array}{l}\text { Total } \\
\text { Cost } \\
\text { (\#/hr.) }\end{array}$ & $\begin{array}{l}\text { Power } \\
\text { Loss } \\
(\mathrm{MW})\end{array}$ \\
\hline 500 & 221.08 & 50 & 84.51 & 50 & 50 & 50 & 6132 & 5.59 \\
\hline 600 & 280.64 & 50 & 127.28 & 50 & 50 & 50 & 7203 & 7.92 \\
\hline 700 & 323.55 & 76.75 & 158.49 & 50 & 51.94 & 50 & 8353 & 10.74 \\
\hline 800 & 355.82 & 99.22 & 181.90 & 50 & 77.41 & 50 & 9559 & 14.34 \\
\hline 900 & 383.07 & 118.31 & 201.36 & 67.35 & 98.41 & 50 & 10813 & 18.51 \\
\hline 1000 & 410.60 & 137.35 & 220.62 & 86.15 & 118.52 & 50 & 12110 & 23.23 \\
\hline 1100 & 425.99 & 155.27 & 238.95 & 104.26 & 138.30 & 65.83 & 13452 & 28.60 \\
\hline 1200 & 459.43 & 171.32 & 255.41 & 120 & 154.43 & 74.02 & 14835 & 34.60 \\
\hline 1300 & 482.90 & 187.66 & 272.32 & 135.38 & 171.68 & 91.31 & 16257 & 41.26 \\
\hline 1400 & 500 & 200 & 292.37 & 150 & 192.54 & 113.95 & 17720 & 48.61 \\
\hline
\end{tabular}




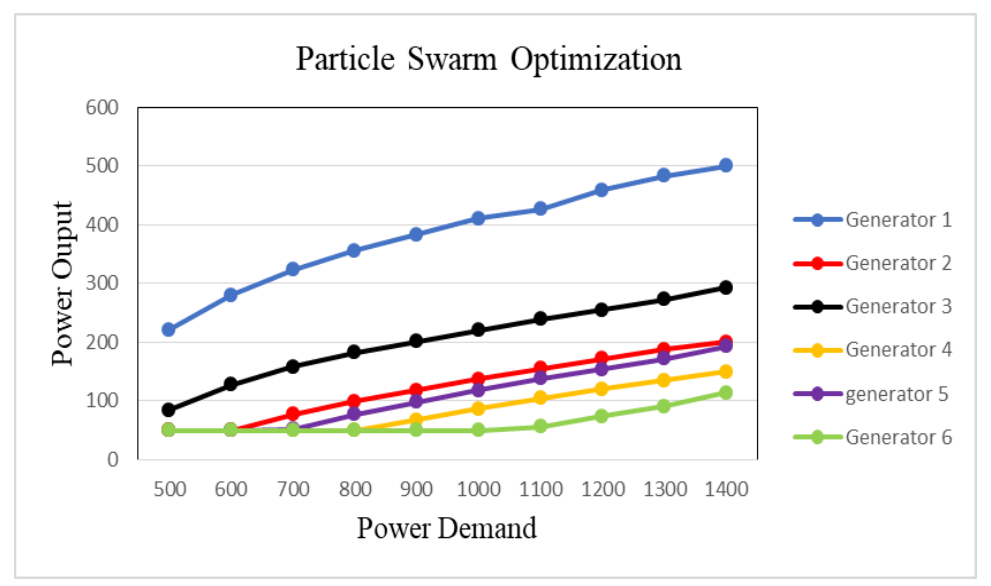

Figure 9 Power output of six generators using Particle Swarm Optimization

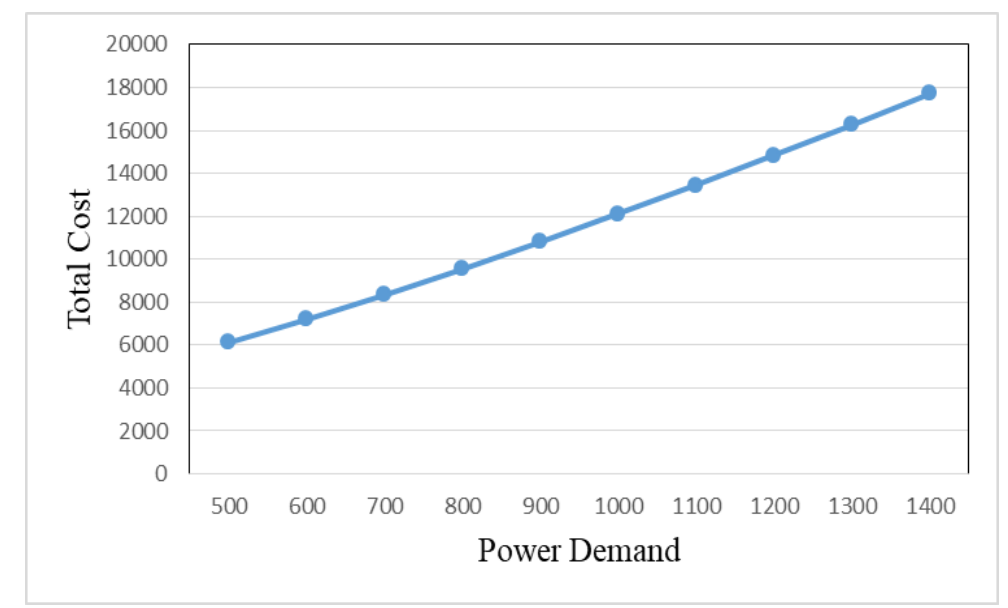

Figure 10 Total cost of generation using Particle Swarm Optimization

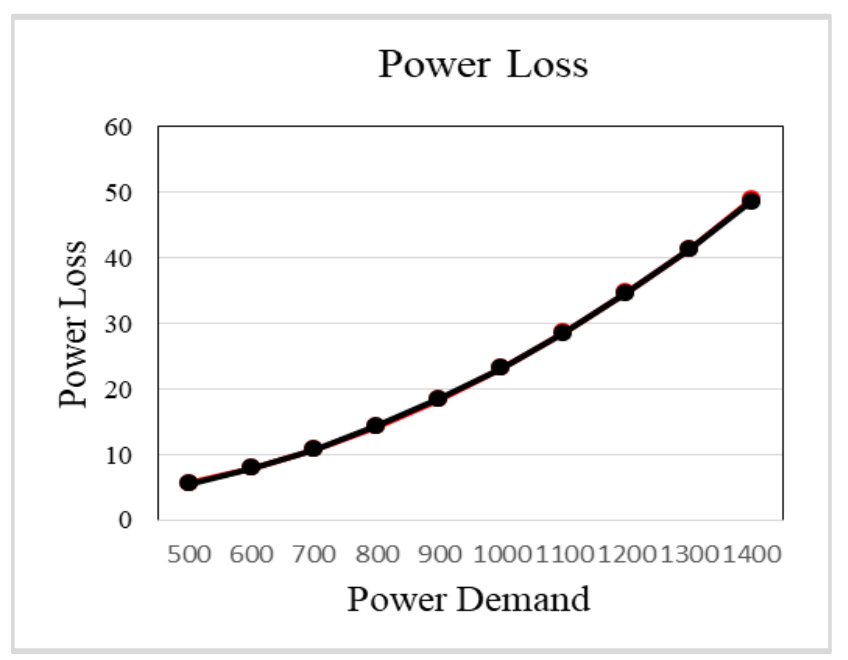

Figure 11 Total Power loss for six generators

Again, the particle swarm optimization gives a slightly different solution for 6-unit system without transmission loss. The solution provided by the particle swarm optimization in terms of generation cost and transmission loss is shown in table 6. 
Table 6 Result by particle swarm optimization without transmission loss at different load values.

\begin{tabular}{|l|l|l|l|l|l|l|l|}
\hline $\begin{array}{l}\text { Power } \\
\text { Demanded } \\
\text { (MW) }\end{array}$ & $\begin{array}{l}\text { Unit 1 } \\
\text { (MW) }\end{array}$ & $\begin{array}{l}\text { Unit 2 } \\
(\mathbf{M W})\end{array}$ & $\begin{array}{l}\text { Unit 3 } \\
\text { (MW) }\end{array}$ & $\begin{array}{l}\text { Unit 4 } \\
\text { (MW) }\end{array}$ & $\begin{array}{l}\text { Unit 5 } \\
\text { (MW) }\end{array}$ & $\begin{array}{l}\text { Unit 6 } \\
\text { (MW) }\end{array}$ & $\begin{array}{l}\text { Total } \\
\text { Cost } \\
\text { (\#/hr.) }\end{array}$ \\
\hline 500 & 215.51 & 50 & 84.49 & 50 & 50 & 50 & 6076 \\
\hline 600 & 271.66 & 50 & 128.34 & 50 & 50 & 50 & 7117 \\
\hline 700 & 312.97 & 72.47 & 158.81 & 50 & 54.76 & 50 & 8229 \\
\hline 800 & 341.88 & 94.26 & 182.53 & 50 & 81.34 & 50 & 9388 \\
\hline 900 & 367.35 & 112.84 & 202.64 & 63.75 & 103.43 & 50 & 10585 \\
\hline 1000 & 391.34 & 130.63 & 221.52 & 82.50 & 124 & 50 & 11817 \\
\hline 1100 & 414.53 & 147.84 & 239.05 & 100.5 & 143.93 & 54.16 & 13082 \\
\hline 1200 & 435.14 & 161.92 & 253.65 & 115.64 & 161.07 & 72.58 & 14376 \\
\hline 1300 & 453.85 & 176.30 & 270.28 & 130.65 & 178.18 & 90.73 & 15698 \\
\hline 1400 & 473.66 & 191.32 & 285.13 & 145.86 & 195.70 & 108.32 & 17047 \\
\hline
\end{tabular}

An economic dispatch problem with multiple fuel options has also been considered. Particle swarm optimization was applied to solve the problem. The parameters of the generating unit as shown in table 7 . The results of the three approaches with multiple fuel option combination are shown in table 8a-8d.

Table 7 Data of 3-unit generator with multiple fuel options.

\begin{tabular}{|l|l|l|l|l|l|l|}
\hline $\begin{array}{l}\text { Generating } \\
\text { Unit }\end{array}$ & $\begin{array}{l}\text { Lower } \\
\text { limit, } \text { Pmin }_{\text {min }}\end{array}$ & $\begin{array}{l}\text { Upper } \\
\text { Limit, } P_{\max }\end{array}$ & FT & $\mathbf{a}$ & B & c \\
\hline 1 & 190 & 490 & 1 & 0.001066 & 0.8773 & 13.92 \\
\cline { 4 - 7 } & & 2 & 0.001597 & -0.5206 & 99.76 \\
\hline 2 & 85 & 265 & 1 & 0.002758 & -0.6348 & 52.85 \\
\cline { 4 - 7 } & & & 2 & 0.001049 & 0.03114 & 1.983 \\
\hline 3 & 200 & 500 & 1 & 0.0002454 & 0.3559 & 43.35 \\
\cline { 3 - 7 } & & & 2 & 0.001165 & -0.2267 & 43.77 \\
\hline
\end{tabular}

Table 8a Comparison of optimization method (Demand $=700 \mathrm{MW}$ ).

\begin{tabular}{|l|l|l|}
\hline Unit & FT & Particle swarm optimization \\
\hline 1 & 1 & 190 \\
\hline 2 & 1 & 207 \\
\hline 3 & 1 & 303 \\
\hline Total Power & & 700 \\
\hline Total Cost & & 432.43 \\
\hline
\end{tabular}


Table 8b Comparison of optimization method (Demand $=700 \mathrm{MW}$ ) with $\mathrm{FT}_{\text {unit } 3}=2$

\begin{tabular}{|l|l|l|}
\hline Unit & FT & Particle swarm optimization \\
\hline 1 & 1 & 190 \\
\hline 2 & 1 & 203.87 \\
\hline 3 & 2 & 306.13 \\
\hline Total Power & & 700 \\
\hline Total Cost & & 340.70 \\
\hline
\end{tabular}

Table 8c Comparison of optimization method (Demand $=700 \mathrm{MW}$ ) with $\mathrm{FT}_{\text {unit } 2,3}=2$

\begin{tabular}{|l|l|l|}
\hline Unit & FT & Particle swarm optimization \\
\hline 1 & 1 & 190 \\
\hline 2 & 2 & 148.34 \\
\hline 3 & 2 & 361.66 \\
\hline Total Power & & 700 \\
\hline Total Cost & & 404.51 \\
\hline
\end{tabular}

\section{Conclusion}

The complex problem of economic power dispatch is solved using particle swarm optimization. The test results clearly demonstrated that particle swarm optimization which is capable of achieving global solutions is simple, computationally efficient and has better and stable dynamic convergence characteristics. For the economic problem for 6-generator system, the particle swarm optimization has also provided the global solution with a high probability. In the case economic dispatch problem with multiple fuel option, the particle swarm optimization has good solution.

However, more research should be done on the effect of changing parameters of particle swarm optimization in solving economic dispatch problem. The parameters should be varied in other to see the behaviour of particle swarm optimization.

\section{Compliance with ethical standards}

\section{Acknowledgments}

Special thanks to TETFUND, Ekiti State University, Ado-Ekiti, Nigeria

\section{Disclosure of conflict of interest}

There are no conflict of interest among the authors

\section{References}

[1] A. J. Wood, B. F. Wollenberg, eacute Shebl\&amp, and Gerald B, 'Power Generation, Operation and Control', p. 658.

[2] M. E. El-Hawary and G. S. Christensen, Optimal economic operation of electric power systems. New York: Academic Press, 1979.

[3] J. Zhu, Optimization of Power System Operation. 2015. doi: 10.1002/9780470466971. 
[4] K. T. Chaturvedi, M. Pandit, and L. Srivastava, 'Self-Organizing Hierarchical Particle Swarm Optimization for Nonconvex Economic Dispatch', IEEE Trans. Power Syst., vol. 23, no. 3, pp. 1079-1087, 2008, doi: 10.1109/TPWRS.2008.926455.

[5] D. C. Walters and G. B. Sheble, 'Genetic algorithm solution of economic dispatch with valve point loading', IEEE Trans. Power Syst., vol. 8, no. 3, pp. 1325-1332, 1993, doi: 10.1109/59.260861.

[6] S. O. Orero and M. R. Irving, 'Economic dispatch of generators with prohibited operating zones: a genetic algorithm approach', IEE Proc. - Gener. Transm. Distrib., vol. 143, no. 6, pp. 529-534, 1996, doi: 10.1049/ipgtd:19960626.

[7] C. Wang and S. M. Shahidehpour, 'Effects of ramp-rate limits on unit commitment and economic dispatch', IEEE Trans. Power Syst., vol. 8, no. 3, pp. 1341-1350, 1993, doi: 10.1109/59.260859.

[8] S. Mirjalili, S. M. Mirjalili, and A. Lewis, 'Grey Wolf Optimizer', Adv. Eng. Softw., vol. 69, pp. 46-61, Mar. 2014, doi: 10.1016/j.advengsoft.2013.12.007.

[9] A. Jaini, I. Musirin, N. Aminudin, M. M. Othman, and T. K. A. Rahman, 'Particle swarm optimization (PSO) technique in economic power dispatch problems', in 2010 4th International Power Engineering and Optimization Conference (PEOCO), Jun. 2010, pp. 308-312. doi: 10.1109/PEOC0.2010.5559236.

[10] J.-B. Park, K.-S. Lee, J.-R. Shin, and K. Y. Lee, 'A Particle Swarm Optimization for Economic Dispatch With Nonsmooth Cost Functions', Power Syst. IEEE Trans. On, vol. 20, pp. 34-42, Mar. 2005, doi: 10.1109/TPWRS.2004.831275.

[11] Zwe-Lee Gaing, 'Particle swarm optimization to solving the economic dispatch considering the generator constraints', IEEE Trans. Power Syst., vol. 18, no. 3, pp. 1187-1195, Aug. 2003, doi: 10.1109/TPWRS.2003.814889.

[12] P. Sriyanyong et al., 'An Approach to Economic Dispatch with Multiple Fuels Based on Particle Swarm Optimization', Toyama City, (Japan), 2011, pp. 327-336. doi: 10.1063/1.3596657.

[13] M. K. Modi, A. Swarnkar, N. Gupta, K. R. Niazi, and R. C. Bansal, 'Stochastic Economic Load Dispatch with Multiple Fuels using Improved Particle Swarm Optimization', IFAC-Pap., vol. 48, no. 30, pp. 490-494, 2015, doi: https://doi.org/10.1016/j.ifacol.2015.12.427.

[14] Jong-Bae Park, Ki-Song Lee, Joong-Rin Shin, and K. Y. Lee, 'A particle swarm optimization for economic dispatch with nonsmooth cost functions', IEEE Trans. Power Syst., vol. 20, no. 1, pp. 34-42, Feb. 2005, doi: 10.1109/TPWRS.2004.831275. 